\title{
UTRICULARIA HUMBOLDTII SCHOMB.
}

Nigel HewitT-CoOPer • The H omestead • Glastonbury R oad • West Pennard • Somerset, BA 6 8N N -UK・sales@hccarnivorousplants.co.uk

Keywords: ecology: U tricularia humboldtii, cultivation.

Of all of the 230 or so species of $U$ tricularia, the sections with the most beautiful flowers are undoubtedly Orchioides and I perua. U tricularia humboldtii falls in to the latter, along with $U$. reniformis, U. nelumbifolia, U. nephrophylla, and U. geminiloba, and indeed I perua translates as "wonderful flower" in the A rawak Indian language.

This plant has the accolade of having the largest flowers in the genus, and al so possibly the largest traps at nearly $1 \mathrm{~cm}$ across (al though the A ustralian ephemeral $U$. arnhemica is also a contender).

Described by Robert Schomburgk in 1840, Utricularia humboldtii is a native of Venezuela, Guyana, and Brazil where, according to Taylor (1989), it is an epiphyte in bromeliad leaf axils or on mossy trees, and also as a sub-aquatic terrestrial in wet soil in open savannah or forest clearings. A s an epiphyte it is sometimes found in the leaf axils of bromeliads, most notably Brocchinia tatei which can attain gigantic proportions (see Fig. 1). A s a terrestrial it is seen in wet peaty soils, generally in highland savannah (see Fig. 2) alongside other U tricularia species amongst grasses where its' characteristic bright green, slightly waxy, coriaceous paddle-shaped leaves can be up to $60 \mathrm{~cm}$ in height, and with a leaf blade up to $10 \mathrm{~cm}$ high and $5 \mathrm{~cm}$ across, held atop red wiry stems (see Fig. 3).

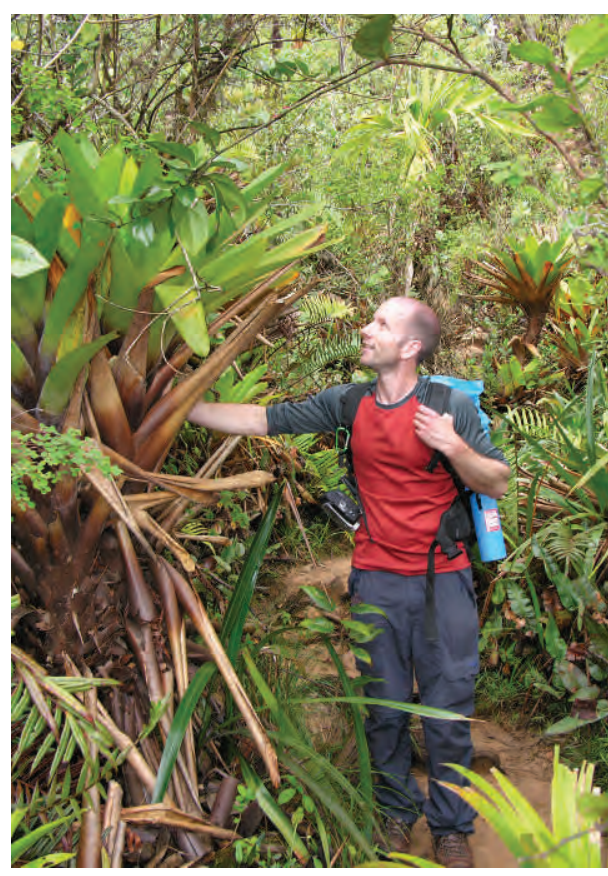

Figure 1: The author with Brocchinia tatei Mount Roraima, Venezuela.

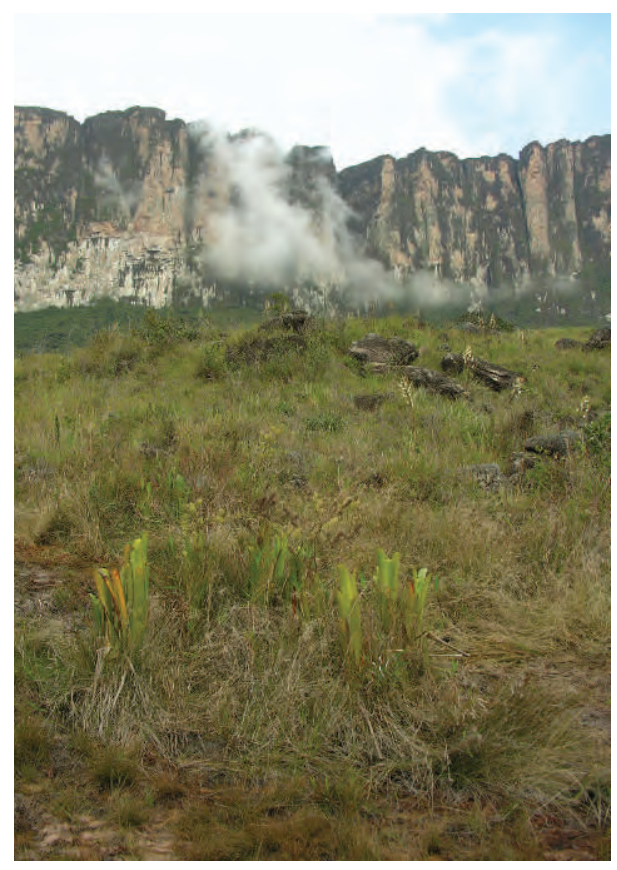

Figure 2: Typical highland habitat with Brocchinia hechtioides. 


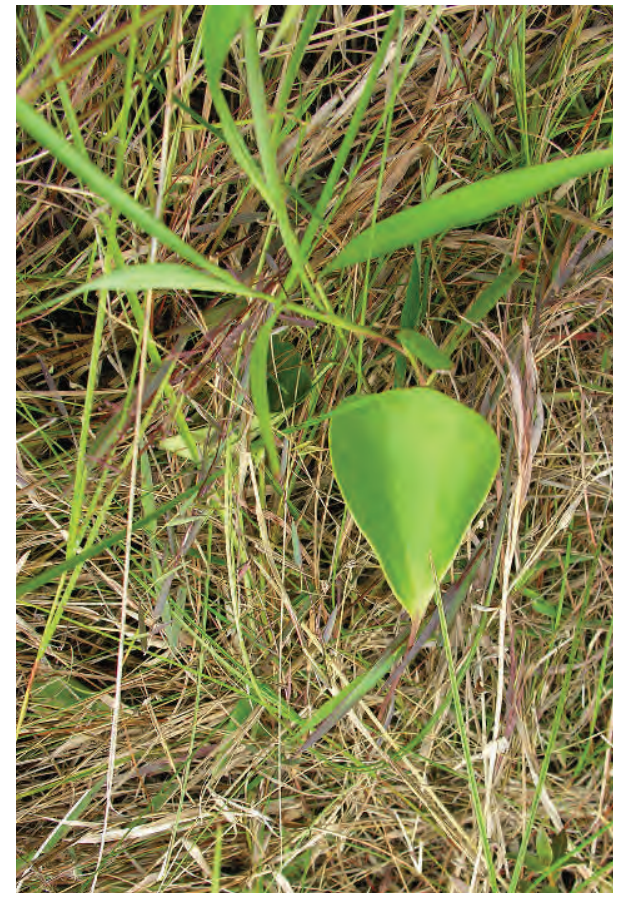

Figure 3: Utricularia humboldtii leaf blade.

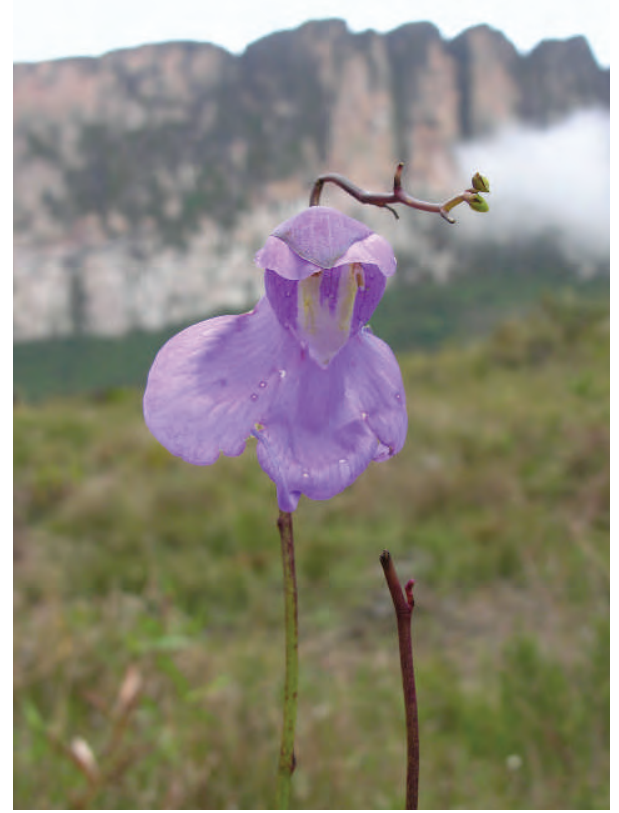

Figure 4: Flowering Utricularia humboldtii with Kukenam Tepui in the background.
Two distinct types of trap are produced, many small ones to $2 \mathrm{~mm}$, and the occasional giant trap to $10 \mathrm{~mm}$ across as mentioned above.

The flowers are this species most notable characteristic. They are up to $7.5 \mathrm{~cm}$ in width and $5 \mathrm{~cm}$ high, dark violet with two vertical bright yellow parallel stripes on the upper corolla lobe. The two calyx lobes on the rear of the flower are a contrasting darker purple (see Fig. 4). U p to 8 flowers are commonly produced on each flower scape, which can be up to 100 $\mathrm{cm}$ in height, circular in cross section, and has a strong wiry quality. Generally, a couple of flowers open simultaneously, starting with the lowest and ending with the highest.

A n interesting phenomenon occurs when this plant is found growing in the axils of bromeliads. Pale green stolons are produced which rise out of the water, arch over, and descend back in to another water source. It was long assumed that this is a method by which the plant can colonise other host bromeliads, but it tends not to travel very far. Certainly in cultivation the stolons tend to only reach a few $\mathrm{cm}$ and so would have little chance of stretching far enough to reach a new host. I thas been suggested that as the host plant grows new leaves from its center, the bladderwort would be gradually pushed out to the dead, and hence dry, outer leaves where it would perish. Therefore, the plant could be replanting itself via stolons back into the centre of the bromeliad to ensure its' survival.

In cultivation this is a fairly forgiving species, and I grow mine in a small pond basket half filled with peat and topped with live sphagnum moss, and stood in $2-5 \mathrm{~cm}$ of rain water. The pot will simply act as a base from which the plant will grow and spread, escaping in to the surrounding water and wandering freely around and between the other pots on the bench in full sun.

I have grown it for a number of years, and it has flatly refused to flower for me. However, my patience recently paid off and I was finally privileged to see this incredible plant flower (see Fig. 5). A lthough it may be coincidence, the in- 
florescence was produced after I inadvertently allowed the water level in the bed to drop dramatically, and I believe it was a panic response on the part of the plant to produce seed prior to dying. Whatever the reason, 4 stunning flowers were produced which lasted approximately 3 weeks. The peculiar characteristic green embryo containing "live" seeds weren't produced, so one assumes either manual pollination is necessary, or the plant is self-sterile.

I was hoping to experiment by allowing the plant to "dry out" this year to see if flowering could be forcibly stimulated, but unfortunately in the cold conditions of the previous winter, the plant appears to have died when the temperature dropped below $7^{\circ} \mathrm{C}$.

A winter minimum of $10^{\circ} \mathrm{C}$ seems to be safe, at which temperature it retains a few evergreen leaves.

As with most U tricularia species, this plant is best propagated from division as it seems fairly vigorous, and further experimentation with allowing the plant to dry a little, may see this traditional shy flowering plant bloom more

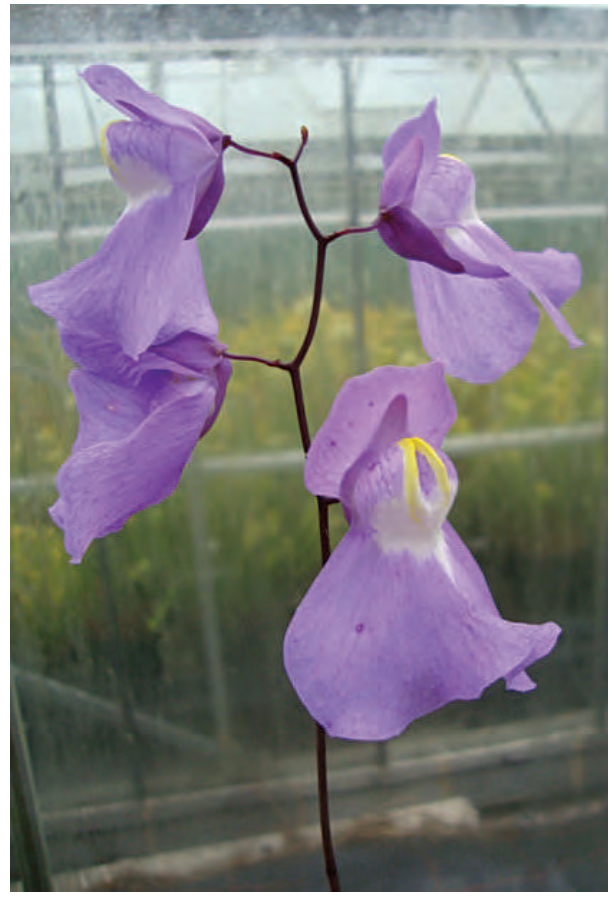

Figure 5: Utricularia humboldtii flowers in cultivation. frequently.

\section{Reference}

Taylor, P. 1989. The genus U tricularia: a taxonomic monograph. Royal Botanic Gardens, Kew, London.

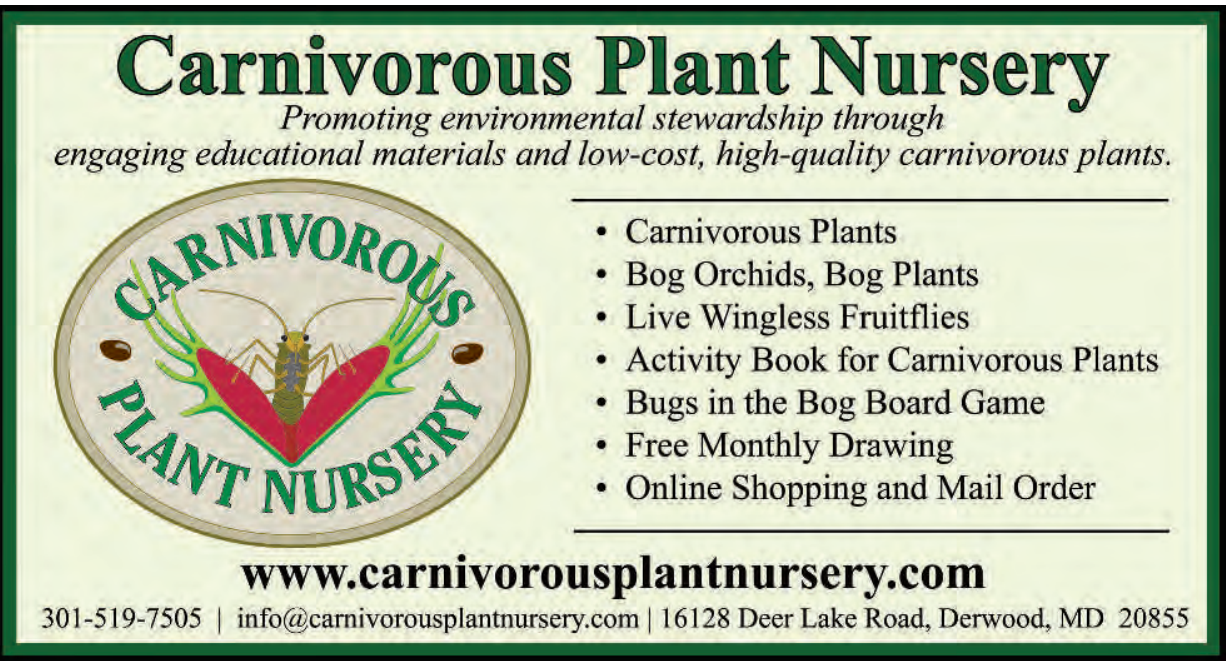

